\title{
Mortality and the concentration of elements in tap water in county boroughs in England and Wales
}

\author{
P. C. ELWOOD AND A. S. ST LEGER \\ From the MRC Epidemiology Unit (South Wales)
}

\author{
M. MORTON \\ From the Tenovus Research Institute, Cardiff
}

SUMMARY To explain the associations of water hardness and air temperature with area differences in ischaemic heart disease mortality, samples of tap water were obtained from homes in 61 county boroughs in England and Wales, and the concentration of calcium and 12 other elements was estimated. Multiple regressions were calculated with the death rates from various causes as dependent variables and with the concentration of the elements in the tap water, mean annual temperature, mean annual rainfall, and a socioeconomic index as independent variables. The well known negative association between water hardness and ischaemic heart disease was shown $\circ$ to be due to calcium, and none of 12 other elements examined appeared to contribute significantly to the association. Area differences in other causes of death also showed an association wit $\varphi$ calcium. There was little association between temperature and ischaemic heart disease.

There is considerable interest in area differences in mortality within Great Britain. These are large, equivalent to a range in standardised mortality ratios (SMRs) for all causes of death from $80-90$ in the south east, to $120-130$ in the north west (West and Lowe, 1976).

The causes of these differences are unknown and a number of environmental factors have been suggested. Greatest interest at present seems to be focused on water (Heyden, 1976) and on temperature (West and Lowe, 1976). One of the early studies in this country (Gardner et al., 1969), examined the association in the county boroughs in England and Wales with populations over 80000 . This identified water hardness, latitude, and rainfall as the main environmental factors to have a statistical association with ischaemic heart disease (IHD) mortality.

We have based our study on that of Gardner et al. (1969) in the hope of elucidating some of the associations they discovered. Our intentions were to examine further the association between water hardness and IHD mortality by determining the interrelationships between trace elements in water. We decided also to study the association between IHD mortality and temperature in an attempt to disentangle the association of this mortality with both water hardness and temperature.

The study was set up with the expectation that if hard water specifically protects against death from
IHD then little association between deaths from other causes, in particular bronchitis, and watem hardness would be observed. Furthermore we. expected that statistical associations, with the concentration of elements in drinking water, would be most noticeable in the 45-64 year age groups because deaths at younger ages could well be atypical and at older ages were likely to be less sensitive to such factors. An association between temperature and bronchitis mortality was expected.

The principal differences between our work and that of Gardner et al. (1969) lie in our set of trace element estimations which were made directly on water samples obtained from each town. In addition we used mean annual temperature. We ignored domestic air pollution and had intended to ignore latitude but for reasons which will emerge in the discussion found it necessary later to incorporate latitude in our analysis.

\section{Method}

The method adopted followed closely that outlined in an earlier study (Elwood et al., 1974). The 1971 census was used to define all towns in England and $\mathrm{N}$ Wales with populations over 80000 . The numbers $\mathrm{W}$ of all deaths and the numbers due to IHD (ICD 410-414) and from chronic bronchitis (ICD 491) 0 were obtained for various age groups from local 
returns for the years 1970-72 inclusive. Some communities were unable to give us a breakdown of deaths by sex, hence our analysis refers to both sexes combined. As there is no reason to claim different hypotheses concerning the aetiology of IHD in men and women we do not consider this omission important, but the 45-64 year age group will be dominated by male deaths.

Random samples of electors were drawn from the lists for each town. In towns with a population of over 20000075 electors were chosen, in towns with a population between 125000 and 20000050 were chosen, and in towns with a population of less than 125000 the sample size was 30 . Each elector drawn was asked to provide a sample of tap water. In 10 towns duplicate samples were requested from each subject. Our earlier study (Elwood et al., 1974) had detected a stronger association between mortality and water trace elements in early morning samples than in samples taken later in the day. We therefore requested early morning samples which included the first run off.

The estimates of the concentrations of the elements in the water on which this report is based were obtained after bulking together the individual samples for each town. Estimations were by atomic absorption spectroscopy and are all stated as parts per million. Individual samples were examined for a few elements to assess variability within towns. In some cases variation was considerable and occasionally the distribution of the concentrations was bimodal which might suggest that the water supplies in these towns were derived from two or more sources. The bulked sample readings did not differ appreciably from the means of individual samples. In those few instances where within town variability was very large it was considered that the bulk reading, although not truly representative of the town, would not bias the results in favour of an association between trace elements and mortality but rather it would tend to weaken such an association.

Duplicate samples were obtained from each subject in 10 towns and these were submitted blind to the laboratory. Analyses of these duplicates gave a measure of the laboratory's consistency. This seemed to be excellent. Samples from the various towns throughout the analysis were presented to the laboratory in random order, so that any unobserved systematic bias in the equipment would not influence the results of entire towns. Some results of our analyses on laboratory consistency and the effects of bulking are summarised in Tables 1 and 2.

Data for mean annual rainfall and mean annual temperature were derived from reports of the Meteorological Office. The socioeconomic index
Table 1 Consistency of laboratory results and sampling strategy. Reproducibility of calcium and magnesium estimation on duplicate samples from two towns with different mean element concentrations

\begin{tabular}{llll}
\hline Element & $\begin{array}{l}\text { Mean reading } \\
\text { (ppm) }\end{array}$ & $\begin{array}{l}\text { No. of } \\
\text { observations } \\
\text { (ignoring } \\
\text { duplicates) }\end{array}$ & $\begin{array}{l}\text { Coefficient of } \\
\text { variation within } \\
\text { duplicates } \\
(\%)\end{array}$ \\
\hline $\begin{array}{l}\text { Town 1 } \\
\text { Calcium }\end{array}$ & 4.47 & 20 & 2.8 \\
$\begin{array}{c}\text { Magnesium } \\
\text { Town 2 }\end{array}$ & 0.90 & 44 & 6.3 \\
$\quad$ Calcium & 59.14 & 28 & 5.4 \\
Magnesium & 4.77 & 27 & 3.4 \\
\hline
\end{tabular}

Table 2 Comparison of bulked sample estimates with means of individual sample estimates for 61 towns

\begin{tabular}{lc}
\hline Element & Coefficient of variation within towns (\%) \\
\hline Calcium & $9 \cdot 7$ \\
Magnesium & $4 \cdot 0$ \\
Copper & $14 \cdot 1$ \\
Zinc & $20 \cdot 0$ \\
\hline
\end{tabular}

(SEI) used was that published in West and Lowe, 1976; this was used to reduce, as far as possible, the expected effects of social and economic differences. It is a covariate rather than a variable of principal interest.

The analysis was based on multiple regressions of each dependent variable (cause specific mortality rates within age groups) on all, and on subsets of the independent variables (concentration of the elements, temperature, rainfall, and SEI). In addition the raw data were plotted and correlation matrices studied. Residuals from the regression were examined but no systematic errors were found. To reduce heterogeneity of error variances which resulted from different population sizes, weighted regressions on logits (Cox, 1970) were used. This transformation leads to the further advantage that the theoretically expected residual mean square is unity and the comparison with the observed error gives an indication of the adequacy of the linear model fitted. A residual mean square greater than expected may imply, among other possible explanations, that the model does not include all the relevant independent variables. Values of Student's $t$ test are based on the observed residual mean square.

It is difficult to determine what statistical significance levels should be used because of the multiplicity of tests required, and because in the regression analysis for each age group and for each cause of death the independent variables are common, and hence interdependent. We have therefore used the $t$ values as a convenient measure of the relative importance of the various independent variables, but these should not be considered as necessarily indicating levels of significance. 


\section{Results}

For various reasons three towns had to be omitted from the total list; this left 61 towns with populations of over 80000 in the 1971 census which were sampled. The response rate of the sample of electors who were asked to provide a sample of tap water was about $80 \%$.

Table 3 displays the means and ranges of the concentrations of the elements in the tap water, the climatic variables, and the SEI. Table 4 sets out for IHD deaths in four age groups the regression coefficients for each transformed independent variable-that is, the 13 elements, temperature, rainfall, and SEI. The $t$ statistics are listed simply as a guide to the relative importance of each independent factor within an age group. The table also indicates the proportions of the variance in death

Table 3 Means and range of the elements and of other related variables

\begin{tabular}{|c|c|c|c|c|}
\hline \multicolumn{2}{|l|}{ Variable } & \multirow[b]{2}{*}{$\begin{array}{c}\begin{array}{c}\text { Mean } \\
\text { ppm }\end{array} \\
0.009 \\
14 \cdot 6 \\
6 \cdot 1 \\
0.15 \\
2 \cdot 08 \\
40 \cdot 4 \\
0.013 \\
0.10 \\
0.16 \\
0.147 \\
0.16 \\
0.060 \\
0.019\end{array}$} & \multirow[b]{2}{*}{$\begin{array}{l}\begin{array}{l}\text { Minimum } \\
\text { ppm }\end{array} \\
0.007 \\
4.4 \\
1.0 \\
0.02 \\
0.32 \\
4.4 \\
0.001 \\
0.03 \\
0.01 \\
0.034 \\
0.03 \\
0.004 \\
0.002\end{array}$} & \multirow[b]{2}{*}{$\begin{array}{c}\begin{array}{l}\text { Maximum } \\
\text { ppm }\end{array} \\
0 \cdot 032 \\
98 \cdot 9 \\
23 \cdot 6 \\
0 \cdot 48 \\
7 \cdot 36 \\
118 \cdot 0 \\
0 \cdot 054 \\
0 \cdot 31 \\
0 \cdot 64 \\
1 \cdot 00 \\
0 \cdot 90 \\
0 \cdot 300 \\
0 \cdot 053\end{array}$} \\
\hline $\begin{array}{l}\text { Lithium } \\
\text { Sodium } \\
\text { Magnesium } \\
\text { Aluminium } \\
\text { Potassium } \\
\text { Calcium } \\
\text { Manganese } \\
\text { Iron } \\
\text { Copper } \\
\text { Zinc } \\
\text { Strontium } \\
\text { Barium } \\
\text { Lead }\end{array}$ & $\begin{array}{l}(\mathbf{L i}) \\
(\mathbf{N a}) \\
(\mathbf{M g}) \\
(\mathbf{A l}) \\
(\mathbf{K}) \\
(\mathbf{C a}) \\
(\mathbf{M n}) \\
(\mathbf{F e}) \\
(\mathbf{C u}) \\
(\mathrm{Zn}) \\
(\mathrm{Sr}) \\
(\mathbf{B a}) \\
(\mathbf{P b})\end{array}$ & & & \\
\hline \multicolumn{2}{|c|}{$\begin{array}{l}\text { Total annual rainfall }(\mathrm{cm}) \\
\text { Mean annual temperature }\left({ }^{\circ} \mathrm{C}\right) \\
\text { Socioconomic index (SEI) }\end{array}$} & $\begin{array}{c}75 \cdot 9 \\
9 \cdot 62 \\
93\end{array}$ & $\begin{array}{l}50 \cdot 8 \\
8 \cdot 28 \\
55\end{array}$ & $\begin{array}{l}119 \cdot 7 \\
11 \cdot 04 \\
167\end{array}$ \\
\hline
\end{tabular}

Concentrations of elements are displayed as the number of decimal places to which they were measured. They are based on the readings made on the bulked samples for each town. rates within each age group which is 'explained' by regression on the 16 independent variables. This statistic indicates that the fit of the regression improves with increasing age except for the most advanced age group.

Calcium makes an important contribution to $\overline{\overline{5}}$ regression in several age groups and its coefficients $\bar{C}$ are all negative-that is, there is a decreasing mortality with increasing concentration of calcium. Several other elements make contributions which are $\stackrel{\mathbb{\Phi}}{\varnothing}$ largely limited to one age group-for example, Fe, \& $\mathrm{Sr}$, and perhaps $\mathrm{Li}$ and $\mathrm{Pb}$. This limited age effect suggests that these associations may be spurious. Neither rainfall nor temperature appears to be important, but in at least two age groups the SEI does contribute towards the regression.

Table 5 displays results in two broad age groups for deaths from all diseases other than IHD and chronic bronchitis, and for deaths from chronic bronchitis. Regression appears to 'explain' a high $\infty$ proportion of the variance in death rates. The $\mathrm{O}$ coefficients for both calcium and iron are mostlog negative although only the contribution from irof is seems to be important in the older age group? $\mathbb{D}$ Manganese shows a positive association wit $\mathbb{R} \stackrel{\mathbb{D}}{7}$ mortality from all causes of death which consistent with a harmful effect. The signs of the coefficients for copper are inconsistent, making $\overrightarrow{0}$ seem unlikely that it is important. Zinc makes. contribution to the regression of deaths from at causes in the older age group. The environmental variables appear to be more important at younger ages, but in the case of chronic bronchitis both temperature and SEI are probably important at all ages.

Table 4 Regression coefficients $\mathrm{b}$ and $\mathrm{t}$ (ignoring sign) for IHD mortality on all the independent variables within four age groups

\begin{tabular}{|c|c|c|c|c|c|c|c|c|}
\hline \multirow{3}{*}{ Independent variable } & \multicolumn{8}{|l|}{ Years } \\
\hline & \multicolumn{2}{|l|}{$35-44$} & \multicolumn{2}{|l|}{$45-54$} & \multicolumn{2}{|l|}{$55-64$} & \multicolumn{2}{|l|}{$65-74$} \\
\hline & $\bar{b}$ & $\mathbf{t}$ & b & $\bar{t}$ & b & $\mathbf{t}$ & $\mathbf{b}$ & $\mathbf{t}$ \\
\hline $\begin{array}{l}\mathbf{L i} \\
\mathbf{N a} \\
\mathbf{M g} \\
\mathrm{Al} \\
\mathbf{K} \\
\mathbf{C a} \\
\mathbf{M n} \\
\mathbf{F e} \\
\mathbf{C u} \\
\mathbf{Z n} \\
\mathbf{S r} \\
\mathbf{B a} \\
\text { Pb } \\
\text { Rainfall } \\
\text { Temperature } \\
\text { SEI }\end{array}$ & $\begin{array}{r}-0.0067 \\
-0.0379 \\
0.0375 \\
-0.0139 \\
-0.0247 \\
-0.1714 \\
0.0102 \\
-0.0623 \\
-0.0117 \\
-0.0519 \\
-0.0006 \\
-0.0349 \\
-0.0129 \\
0.0124 \\
-0.0596 \\
-0.0215\end{array}$ & $\begin{array}{l}0 \cdot 2 \\
0 \cdot 6 \\
0 \cdot 7 \\
0 \cdot 4 \\
0 \cdot 3 \\
1 \cdot 8 \\
0 \cdot 2 \\
1 \cdot 5 \\
0 \cdot 2 \\
1 \cdot 1 \\
0 \cdot 0 \\
1 \cdot 0 \\
0 \cdot 4 \\
0 \cdot 3 \\
1 \cdot 5 \\
0 \cdot 6\end{array}$ & $\begin{array}{r}-0.0029 \\
-0.0203 \\
-0.0016 \\
-0.0060 \\
-0.0014 \\
-0.1519 \\
0.0150 \\
-0.0537 \\
0.0281 \\
-0.0147 \\
-0.0043 \\
-0.0358 \\
-0.0222 \\
0.0066 \\
-0.0339 \\
-0.0987\end{array}$ & $\begin{array}{l}0 \cdot 1 \\
0 \cdot 5 \\
0 \cdot 0 \\
0 \cdot 3 \\
0 \cdot 0 \\
2 \cdot 2 \\
0 \cdot 4 \\
1 \cdot 8 \\
0 \cdot 7 \\
0 \cdot 5 \\
0 \cdot 1 \\
1 \cdot 4 \\
0 \cdot 9 \\
0 \cdot 2 \\
1 \cdot 3 \\
4 \cdot 0\end{array}$ & $\begin{array}{r}0.0226 \\
-0.0187 \\
-0.0340 \\
0.0078 \\
-0.0183 \\
-0.1514 \\
0.0340 \\
-0.0444 \\
0.0222 \\
-0.0317 \\
0.0600 \\
-0.0085 \\
-0.0289 \\
-0.0100 \\
-0.0258 \\
-0.0161\end{array}$ & $\begin{array}{l}1 \cdot 4 \\
0 \cdot 7 \\
1 \cdot 4 \\
0 \cdot 5 \\
0 \cdot 6 \\
3 \cdot 6 \\
1 \cdot 5 \\
2 \cdot 3 \\
0 \cdot 8 \\
1 \cdot 7 \\
2 \cdot 5 \\
0 \cdot 5 \\
1 \cdot 8 \\
0 \cdot 5 \\
1 \cdot 5 \\
1 \cdot 5\end{array}$ & $\begin{array}{r}0.0283 \\
0.0394 \\
-0.0236 \\
-0.0041 \\
-0.0537 \\
-0.0549 \\
0.0218 \\
-0.0150 \\
0.0184 \\
-0.0093 \\
0.0111 \\
-0.0037 \\
-0.0289 \\
0.0033 \\
-0.0168 \\
-0.0362\end{array}$ & 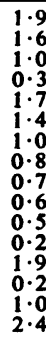 \\
\hline$\% \mathbf{S S}^{*}$ & \multicolumn{2}{|c|}{$54 \cdot 2$} & \multicolumn{2}{|c|}{$66 \cdot 5$} & \multicolumn{2}{|c|}{$70 \cdot 7$} & \multicolumn{2}{|c|}{$52 \cdot 8$} \\
\hline
\end{tabular}

* Percentage of the total variance 'explained' by multiple regression on all variables.

The independent variables have been standardised to zero mean and unit variance thus the regression coefficients are also standardised. 
Table 5 Standardised regression coefficients $\mathrm{b}$ and $\mathrm{t}$ (ignoring sign) for all causes of death (except IHD and bronchitis) and for chronic bronchitis mortality in two age groups

\begin{tabular}{|c|c|c|c|c|c|c|c|c|}
\hline \multirow[t]{3}{*}{ Independent variable } & \multicolumn{4}{|c|}{$\begin{array}{l}\text { All causes } \\
\text { (except for IHD and bronchitis) }\end{array}$} & \multicolumn{4}{|c|}{ Chronic bronchitis } \\
\hline & \multicolumn{2}{|c|}{$45-64$ years } & \multicolumn{2}{|c|}{$65+$ years } & \multicolumn{2}{|c|}{$45-64$ years } & \multicolumn{2}{|c|}{$65+$ years } \\
\hline & $\bar{b}$ & $\mathbf{t}$ & $\mathbf{b}$ & t & b & $\mathbf{t}$ & b & $t$ \\
\hline $\begin{array}{l}\mathbf{L i} \\
\mathbf{N a} \\
\mathbf{M g} \\
\mathbf{A l} \\
\mathbf{K} \\
\mathrm{Ca} \\
\mathrm{Mn} \\
\mathrm{Fe} \\
\mathrm{Cu} \\
\mathrm{Zn} \\
\mathrm{Sr} \\
\mathrm{Ba} \\
\mathbf{P b} \\
\text { Rainfall } \\
\text { Temperature } \\
\text { SEI }\end{array}$ & $\begin{array}{r}0.0040 \\
-0.0131 \\
-0.0309 \\
0.0086 \\
-0.0004 \\
-0.0762 \\
0.0301 \\
-0.0581 \\
0.0469 \\
-0.0080 \\
-0.0205 \\
0.0054 \\
0.0168 \\
-0.0429 \\
-0.0245 \\
-0.0463\end{array}$ & $\begin{array}{l}0 \cdot 3 \\
0 \cdot 6 \\
1 \cdot 5 \\
0 \cdot 7 \\
0 \cdot 0 \\
2 \cdot 2 \\
1 \cdot 6 \\
3 \cdot 6 \\
2 \cdot 1 \\
0 \cdot 5 \\
1 \cdot 1 \\
0 \cdot 4 \\
1 \cdot 2 \\
2 \cdot 7 \\
1 \cdot 7 \\
3 \cdot 6\end{array}$ & $\begin{array}{r}0.0004 \\
-0.0113 \\
0.0036 \\
-0.0147 \\
0.0122 \\
0.0015 \\
0.0398 \\
-0.0219 \\
-0.0116 \\
-0.0222 \\
-0.0164 \\
0.0128 \\
0.0115 \\
0.0003 \\
0.0025 \\
0.0066\end{array}$ & $\begin{array}{l}0.0 \\
0 \cdot 7 \\
0 \cdot 2 \\
1 \cdot 4 \\
0.6 \\
0 \cdot 0 \\
2 \cdot 7 \\
1 \cdot 7 \\
0 \cdot 7 \\
2 \cdot 3 \\
1 \cdot 2 \\
1 \cdot 2 \\
1 \cdot 1 \\
0 \cdot 0 \\
0 \cdot 2 \\
0.7\end{array}$ & $\begin{array}{r}0.0206 \\
-0.0434 \\
-0.0152 \\
0.0667 \\
-0.0017 \\
-0.2613 \\
0.0525 \\
-0.1971 \\
0.0275 \\
0.0023 \\
0.0304 \\
-0.0255 \\
0.0336 \\
-0.0726 \\
-0.1145 \\
-0.1418\end{array}$ & $\begin{array}{l}0.5 \\
0.6 \\
0 \cdot 2 \\
1 \cdot 8 \\
0.0 \\
2 \cdot 4 \\
0.9 \\
4 \cdot 1 \\
0 \cdot 4 \\
0 \cdot 0 \\
0 \cdot 5 \\
0.6 \\
0.8 \\
1 \cdot 6 \\
2 \cdot 6 \\
3 \cdot 5\end{array}$ & $\begin{array}{r}-0.0099 \\
0.0456 \\
0.0119 \\
0.0012 \\
-0.0520 \\
-0.0745 \\
0.0272 \\
-0.0882 \\
0.0079 \\
-0.0184 \\
-0.0388 \\
0.0201 \\
0.0272 \\
0.0001 \\
-0.0737 \\
-0.0828\end{array}$ & $\begin{array}{l}0.3 \\
0.9 \\
0.2 \\
0.0 \\
0.8 \\
0.9 \\
0.6 \\
2 \cdot 3 \\
0.2 \\
0.5 \\
0.8 \\
0.6 \\
0.8 \\
0.0 \\
2.2 \\
2.7\end{array}$ \\
\hline$\% \mathbf{S S}^{*}$ & \multicolumn{2}{|c|}{$68 \cdot 7$} & \multicolumn{2}{|c|}{$42 \cdot 4$} & \multicolumn{2}{|c|}{$63 \cdot 6$} & \multicolumn{2}{|c|}{$54 \cdot 6$} \\
\hline
\end{tabular}

*Percentage of the total variance 'explained' by multiple regression on all variables.

The independent variables were divided into two groups, the concentrations of the elements and the climatic variables together with the SEI. In Table 6 the relative importance of these groups in the overall regression is compared. Both groups contribute significantly to regression and do so, at least in part, independently, although there are certain cross correlations such as that of rainfall with calcium (in our data $r=-0.5$ for these variables). Table 6 indicates that on the whole the elements in the tap water contribute more to the regression than the climatic variables and SEI.

Table 6 Comparison of the contribution of the concentration of all the elements with that of temperature, rainfall, and SEI as a group to the fit of the regression on IHD mortality

\begin{tabular}{|c|c|c|c|c|}
\hline \multirow{2}{*}{$\begin{array}{l}\text { Age group } \\
\text { (years) }\end{array}$} & \multicolumn{2}{|l|}{ F ratio } & \multicolumn{2}{|c|}{$\%$ SS accounted for } \\
\hline & Elements & Other variables & Elements & Other variables \\
\hline $\begin{array}{l}35-44 \\
45-54 \\
55-64 \\
65-74\end{array}$ & $\begin{array}{l}2 \cdot 3 \\
2 \cdot 3 \\
4 \cdot 2 \\
1 \cdot 6\end{array}$ & $\begin{array}{l}0 \cdot 9 \\
6 \cdot 1 \\
1 \cdot 5 \\
2 \cdot 5\end{array}$ & $\begin{array}{l}51 \cdot 4 \\
52 \cdot 6 \\
67 \cdot 8 \\
44 \cdot 9\end{array}$ & $\begin{array}{l}23 \cdot 0 \\
43 \cdot 4 \\
34 \cdot 4 \\
29 \cdot 8\end{array}$ \\
\hline
\end{tabular}

The $F$ ratio is the ratio of the contribution of the group of variables to the full model. \% SS is the percentage of the variance accounted for by the set of variables alone, with the other group omitted.

The contribution of calcium is the most important. For example, regression on calcium alone accounts for $42 \%$ of the variance in IHD death rates (55-64 years) while strontium and iron, the only other notable elements in this age group, account alone for only $12 \%$ and $10 \%$. On the other hand, within the other group of variables shown in Table 6, SEI far outweighs rainfall or temperature. Indeed the relatively high $F$ ratios attributable to the other variables in Table 6 within the age group 45-54 years is accounted for almost entirely by SEI.

\section{Discussion}

In the introduction we stated our hypotheses and expectations and now we consider how far these have been fulfilled. Tables 4 and 5 show that the association with calcium is obvious for IHD mortality at most ages but it is also noticeable for total mortality and for mortality from chronic bronchitis although only at ages under 65 years. Calcium is important in IHD mortality whether considered alone or together with all the other variables, whereas temperature shows an important effect only if the trace elements are ignored. Temperature on its own is important only in the case of bronchitis deaths at all ages, and of mortality from all causes at ages under 65 years.

Iron is the only other element which, in the present data, appears to merit serious consideration. However we are reluctant to conclude that there is a real association. Firstly we had no prior hypothesis relevant to this element and the contribution of iron to the regression emerged as an unexpected finding. Secondly, although few workers seem to have considered iron in this context, Schroeder et al. (1974) found no evidence of any significant correlation of it with any cause of death.

In view of the nature of regression analysis and of the complex intercorrelations between variables it is not possible to draw causal conclusions. There is, however, evidence that the concentrations of elements in tap water go some way towards explaining area differences in mortality but that the effect does not seem to be specific to IHD mortality. 
Statistically the single most important element is calcium and we can assert that the well known association between water hardness and mortality is not explained away in terms of associations between mortality and any of the 12 other elements we have studied. Neither rainfall nor temperature has much to contribute in explaining the differences in IHD mortality between towns in England and Wales.

Our results are similar to those of Gardner et al. (1969) which is hardly surprising since we used almost the same populations at roughly the same time. There may seem to be one inconsistency between our results and theirs in that we failed to find an association between IHD deaths and temperature whereas Gardner et al. found a marked association between IHD deaths and latitude. $A$ priori one would expect temperature and latitude to be strongly associated but the presence of, for example, inland-coastal and east-west temperature gradients at any given latitude would make it unlikely that the two variables temperature and latitude could be interchanged for our purposes. We examined this by re-analysing our data with latitude substituted for temperature. We found a correlation coefficient of 0.7 between temperature and latitude and we confirmed the strong association between IHD deaths and latitude found by Gardner $e t$ al. It is clear that whatever the effect of latitude on IHD mortality may be, a negligible proportion of this can be attributed to temperature. This raises the interesting question-What is the reason for the association with latitude? We believe that it may, in part, reflect social factors not included in the socioeconomic indices of either Gardner et al. (1969) or West and Lowe (1976).

There is one other study which must be considered in the light of our findings. West and Lowe (1976) show a strong association between IHD mortality and temperature in an analysis of all 115 county and London boroughs of England and Wales (1969-71). Our boroughs are a subset of these. West and Lowe do not include calcium or other elements in their analysis and we have shown (not published) that this accounts for some of the difference between their results and ours. Furthermore, West and Lowe included about 30 London boroughs, or boroughs close to London, which were excluded from our list of county boroughs and as most London boroughs record low IHD mortality and high temperatures this has led to an apparently greater effect of $\infty$ temperature than we found in our data. Similarly, most of the boroughs with a high SEI are found in $?$ or around London, hence this may explain the $\stackrel{\varnothing}{\varrho}$ stronger SEI effect demonstrated by West and Lowe. It is difficult to know what is the most appropriate $\stackrel{5}{?}$ method of sampling towns or other areas for $\bar{C}$ comparative studies such as this one and we propose $\frac{\overline{ }}{\bar{n}}$ to investigate further the effect of different groupings. $\frac{\bar{D}}{\bar{D}}$

Temperature undoubtedly has a marked temperal $\stackrel{\mathbb{Q}}{\unrhd}$ association with mortality within an area. However, this does not imply an effect between areas as these two possible roles are conceptually different. In fact the present data are inconsistent with temperature $\vec{\omega}$ being a major cause of difference in mortality between areas, and the association between the concentration of calcium in water and mortality remains, despite attempts to explain it away in terms of other variables.

We thank Dr $R, R$ West and Profesor $C . R$. Lowe for making available to us, while their paper was im preparation, their socioeconomic index.

Reprints from P. C. Elwood, MRC Epidemioloo Unit (South Wales), 4 Richmond Road, Cardi CF2 3AS.

\section{References}

Cox, D. R. (1970). The Analysis of Binary Data. Methuen: London.

Elwood, P. C., Abernethy, M., and Morton, M. (1974). Mortality in adults and trace elements in water. Lancet, 2, 1470-1472.

Gardner, M. J., Crawford, M. D., and Morris, J. N. ำ (1969). Patterns of mortality in middle and early old age in the county boroughs of England and Wales. British Journal of Preventive and Social Medicine, 23, 133-140.

Heyden, S. (1976). The hard facts behind the hard-water theory and ischemic heart disease. Journal of Chronic $\stackrel{\bigcirc}{\rightarrow}$ Diseases, 29, 149-157.

Schroeder, H. A., Kraemer, L. A., and Brattleboro, V. (1974). Cardiovascular mortality, municipal water, and corrosion. Archives of Environmental Health, 28, 윽 303-311.

West, R. R., and Lowe, C. R. (1976). Mortality from 욱 ischaemic heart disease: Inter-town variation and its $D$ association with climate in England and Wales. International Journal of Epidemiology, 5, 195-201. 